\title{
Evaluation of a Novel Road Thermoelectric Generator System
}

\author{
Seyed Amid Tahami*, Mohammadreza Gholikhani, Reza Nasouri, and Samer Dessouky \\ Department of Civil and Environmental Engineering, Univ. of Texas at San Antonio, TX 78249, United States
}

\begin{abstract}
Capturing the unused energy is the challenging aspect in the harvesting process. Since one potentially important component for energy harvesting in the transportation sector is pavement, successful energy harvesting from roadway pavements can lead to sustainable transportation infrastructure systems. Asphalt pavement surface temperature can reach up to $70^{\circ} \mathrm{C}$ in summer because of solar radiation. This paper presents a development of novel set of road thermoelectric generator system and describes the operation, design, and performance of the system installed within pavement that captures the heat energy from the temperature differential between the pavement surface and the subgrade soil. Designed prototype encompasses of thermoelectric generator, coolant module, heat collector and conductor. The efficiency and performance of the designed system were evaluated through the experiments and finite element modeling. Based on the results, the generated electrical power from the asphalt pavement could be a key source for providing off-grid power supply for sensors used in smart infrastructure, structural health monitoring, and environment sensing.
\end{abstract}

\section{Introduction}

Energy harvesting stands alone as one of the most promising approaches to mitigate the fossil fuel depletion and environmental degradation. Energy harvesting is a process that captures unused ambient energy that would otherwise be lost as heat, light, sound, vibration, stress or movement. Solar energy is undoubtedly recognized as the unlimited and environment friendly energy resource. Recently, pavement infrastructures have drawn attention to be used as a renewable source for energy harvesting purposes. Solar radiation can be absorbed by asphalt pavement causing an increase in the temperature of asphalt pavements. Roadways are widely used in the transportation sector to connect communities and moving people and goods around the world. Pavements have been built over billions of kilometers long worldwide, among which over 6 million kilometers are allotted to the United States $[1,2]$.

Solar radiation absorbed by pavement surface causes temperature increase within pavement. Thermoelectric generators (TEGs) are ideal candidates for harvesting energy in asphalt pavement roadways as they convert thermal energy into electrical power. TEG can convert heat into electrical energy based on the Seebeck effect. Using TEGs offer several benefits such as environmentally friendly energy, no moving mechanical components and low maintenance requirements [3].

In the research carried out by $\mathrm{Wu}$ et al. [4], the application of TEGs for production of electrical energy in pavement was investigated. They showed that to generate electricity the temperature difference between the pavement surface and the surrounding soil (deep inside the ground) can be utilized. In this study one side of the
TEG device was attached directly to asphalt mix and another was attached to plate embedded in the soil. However, using such an approach might compromise their longevity due to the immediate exposure of TEGs to the cyclic mechanic [4].

Researchers at University of Texas at San Antonio developed two experimental Z-shape models to utilize the temperature differences between the subgrade and road surface which facilitated the electricity generation by TEG. For the cooling process, two heat sinks, buried at underground and filled with water and soil, separately, were attached to TEGs [5]. A more recent work, done by Jiang et al. [6], used rectangular aluminum vapor chambers to transfer captured heat to the TEGs. The other side of the TEG is exposed to a tank filled with water, and placed next to the pavement edge under a shading board [6].

\section{Objectives}

In this study, the energy harvest system was developed by optimizing the heat transfer mechanism and proposing an innovative cooling technique.

The objectives of this research are:

- Determine the optimized design of harvester prototype using Finite Element (FE) analysis.

- Field testing of a fabricated harvester prototype to estimate power output.

\section{Thermoelectric theory}

A thermoelectric module is typically composed of n- and p-type legs, providing the ability for electrons to move

\footnotetext{
* Corresponding author: seyedamid.tahami@utsa.edu
} 
freely through metals and semiconductors [7]. Voltage value is given by the following equation [8]:

$$
V=\alpha\left(T_{h}-T_{c}\right)
$$

where $\mathrm{V}$ is the voltage of the TEG, $\mathrm{T}_{\mathrm{h}}$ is the hot side temperature of the TEG, $T_{c}$ is the cold side temperature of the TEG, and $\alpha$ is the Seebeck coefficient of the TEG.

In addition, the current, electrical power and the total amount of heat can be obtained using the following equations $[8,9]$ :

$$
\begin{aligned}
& I=V /\left(R+R_{l}\right) \\
& P=Q_{h}-Q_{c}=I^{2} R_{l} \\
& Q=\alpha I T_{c}+K\left(T_{h}-T_{c}\right)-1 / 2 I^{2} R_{l}
\end{aligned}
$$

where $I$ is the current, $R$ is the internal resistance of TEG, $\mathrm{R}_{\mathrm{L}}$ is the Load resistance, $\left(\mathrm{Q}_{\mathrm{h}}-\mathrm{Q}_{\mathrm{c}}\right)$ is the heat flux due to temperature gradient, $\mathrm{Q}$ is the total quantity of heat, and $\mathrm{K}$ is the heat transfer coefficient.

\section{Materials and methods}

The assembled energy harvesting system is shown in Figure 1. As it can be seen, the system consisted of four segments such as the L-shape copper plate as heat collector and heat conductor, TEGs, heat sink, and insulation box. The L-shape copper plate with the thickness of $0.15 \mathrm{~cm}$ consisted of two segments; A Heat receiver with $50 \mathrm{~cm}$ length is embedded at $3 \mathrm{~cm}$ depth of pavement, A Heat conductor, the vertical segment, is placed near soil up to $18 \mathrm{~cm}$ depth (Figure 2). Two TEGs were used to convert the thermal energy into electrical power. The hot side of TEGs were attached to the copper plate with thermal paste and the cold sides connected to the heat sink. An aluminum heat sink with size of $18 \times 10$ $\times 5 \mathrm{~cm}$ was implemented for cooling purposes. A latent heat storage system using phase change material was used to fill this coolant system to store the thermal energy.

The Insulation Box was also designed as a thermalbarrier to prevent conducting heat to heat sink from ambient (Figure 1).

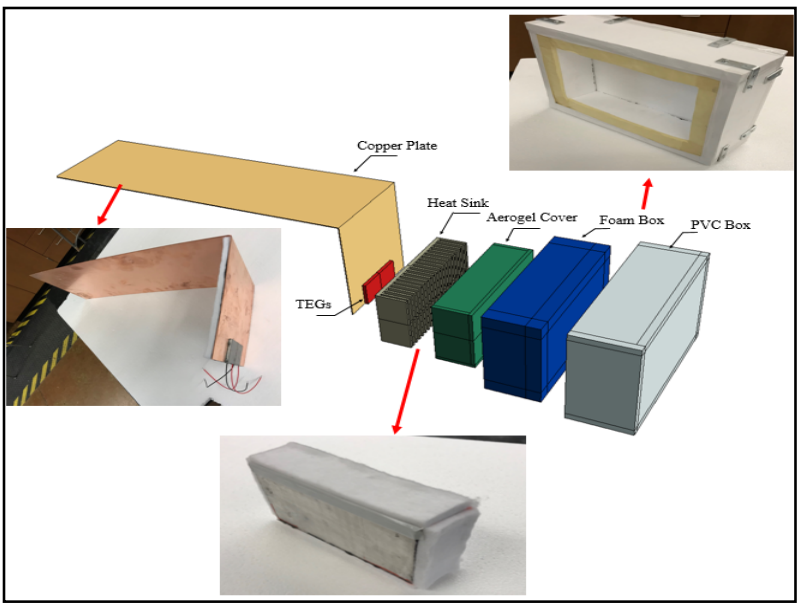

Fig. 1. The harvester prototype components.
In this way, the heat sink can perform ideally to provide a cooling effect, consequently leads to higher temperature difference within TEG. The insulation box consisted of three layers; the first layer exposed to ambient, is made of Polyvinylchloride; expanded Styrofoam with $2 \mathrm{~cm}$ thickness and was used as second layer; the third layer, which is in contact with heat sink, is Aerogel cover with $1 \mathrm{~cm}$ thickness.

The description and schematic of prototype is illustrated in Figure 2. The copper plate was embedded at $3 \mathrm{~cm}$ depth under pavement surface.

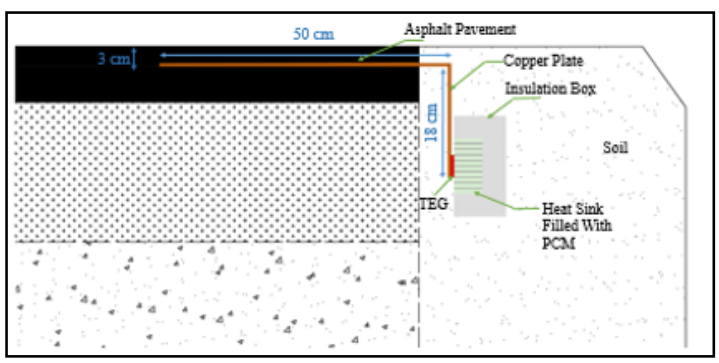

Fig. 2. Schematic of the thermoelectric energy harvesting prototype in pavement.

\section{Finite element model results and discussions}

Finite element (FE) simulations were performed to determine the temperature distribution within the prototype. Simulating the prototypes is a proper approach to determine the optimum material and design shape for effective energy harvesting prototypes. In addition, the employed boundary conditions consisted of applying heat flux to top plate and temperature of $30{ }^{\circ} \mathrm{C}$ to the outer surface of insulation box. Also, the brick mesh with size of $4 \mathrm{~mm} \times 4 \mathrm{~mm} \times 2 \mathrm{~mm}$ was used for simulation. The temperature variation at depths of 3, 15, 20 and $25 \mathrm{~cm}$ were measured in the field over five sunny days in San Antonio, TX (Figure 3). The measured temperatures were used for simulations.

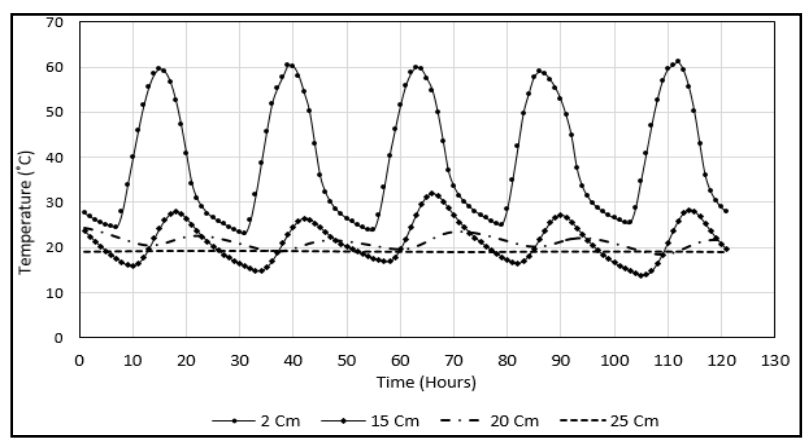

Fig. 3. Temperature profile (four depths) for five days in San Antonio, TX.

In order to find the proper material for the heat collector and conductor plate, three materials were selected and analyzed to determine which material could perform effectively to transfer thermal energy. Figure 4 represents the analysis of the prototypes modeled with 
different materials such as copper, aluminum and steel with thermal conductivity of $386 \mathrm{~W} / \mathrm{m} * \mathrm{~K}, 204 \mathrm{~W} / \mathrm{m} * \mathrm{~K}$ and $48 \mathrm{~W} / \mathrm{m}^{*} \mathrm{~K}$, respectively. Based on the FE results, the copper plate could yield the temperature of $41^{\circ} \mathrm{C}$ at bottom of vertical segment zone, which is the highest value among the models. Besides, the Aluminum and steel models revealed 37 and $24^{\circ} \mathrm{C}$, respectively. Therefore, it can be inferred that the copper plate would be more proper material for the proposed prototype.
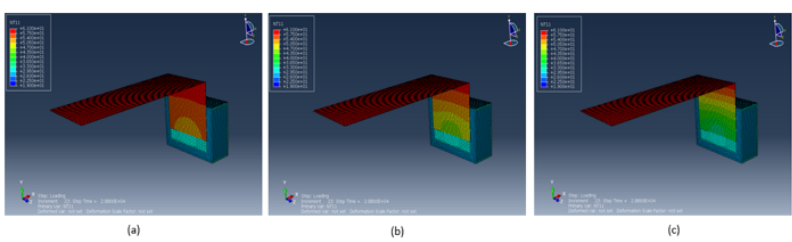

Fig. 4. FE modeling; (a) copper plate, (b) aluminum plate, (c) steel plate.

In addition, two designs, L-shape and Z-shape, were evaluated to determine which shape would have better potential for transferring heat from asphalt pavement (Figure 5). FE analysis suggested that the top plate (collector plates) of both designs could experience temperature of $49^{\circ} \mathrm{C}$, while the L-shape design could be the optimum design for the prototype due to greater capacity to transfer the heat. Because, the $\mathrm{Z}$-shape design revealed the temperature of $30^{\circ} \mathrm{C}$ which is much lower than L-shape design (i.e., $41^{\circ} \mathrm{C}$ ). Also, the temperature of heat sink was remained around $18-19^{\circ} \mathrm{C}$ over 8 hours meaning that the heat sink insulation performed properly.

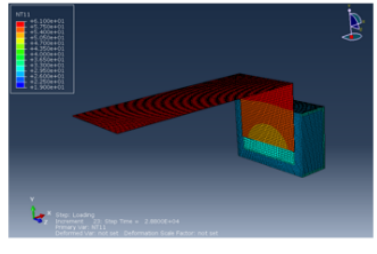

(a)

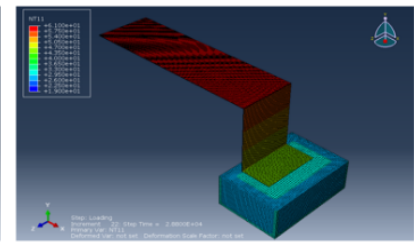

(b)
Fig. 5. FE modeling; (a) L-shape, (b) Z-shape.

\section{Experimental results}

A slab (Figure 6) was prepared with $60 \mathrm{~mm}$ thick HMA (dense graded hot mix asphalt typically used for surface) layer, with a copper plate embedded inside.

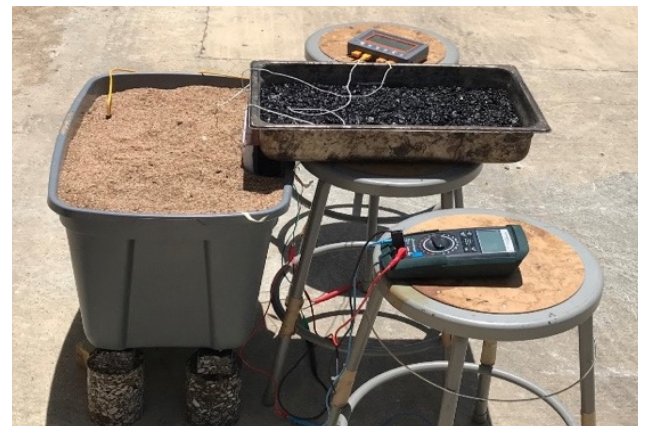

Fig. 6. Data collection.
Figure 7 represents the output power for $8 \mathrm{~h}$ testing. The energy harvester system produced an average output power of $29 \mathrm{mWatt}$. As it can be seen, the system could generate $34 \mathrm{mWatt}$ as the maximum power the maximum power between 2:00 pm and 2:30 pm.

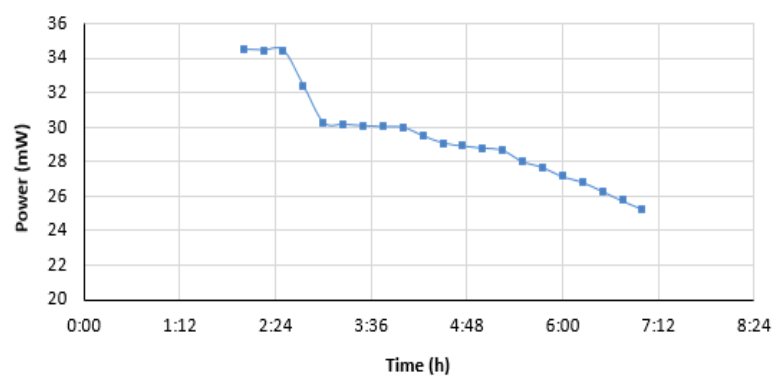

Fig. 7. Output power over 8 hours.

Additionally, the output power varies over the time by variation of the thermal gradient (Figure 8). The results showed that by decrease of thermal gradient, the rate of electric power generation dropped $25 \%$. Hence, a direct correlation between thermal gradient and power output can be found imping that the higher the thermal gradient, the more the energy can be harvested. The field data (Figure 8) revealed that the temperature of top plate and heat sink were about $50^{\circ} \mathrm{C}$ and $18^{\circ} \mathrm{C}$, respectively, which are consistent with $\mathrm{FE}$ analyses results.
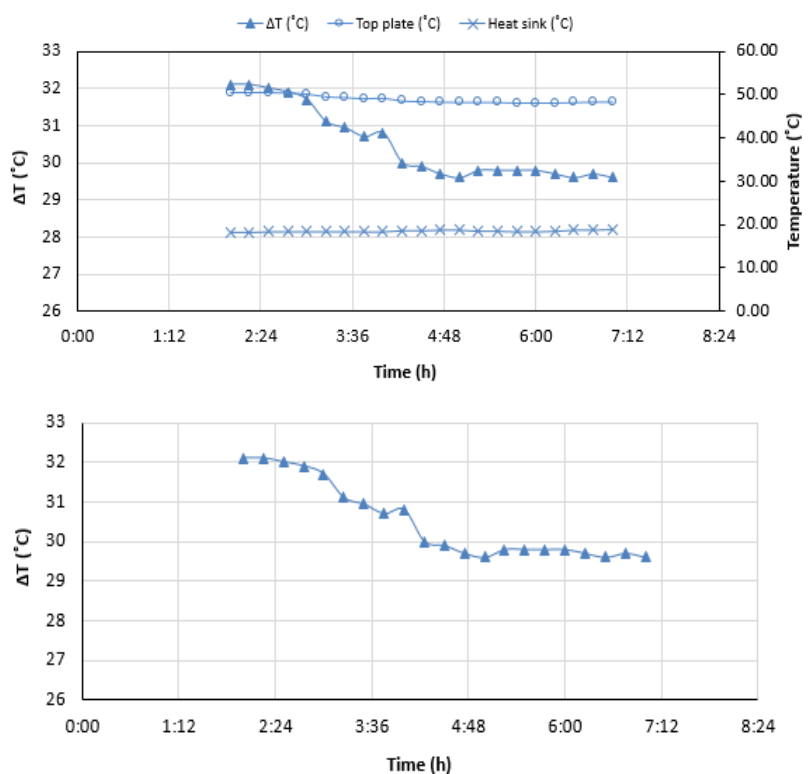

Fig. 8. Temperature difference over 8 hours.

\section{Conclusions}

In this study a road thermoelectric generator system was developed for electricity generation. From FE simulations and field test, the optimum design and the effectiveness of the system were evaluated. Based on the results, the followings findings are presented.

- Based on FE simulations, the L-shape plate showed the optimum design for heat transferring. In addition, the copper plate could have better performance for the prototype. 
- The use of cooling module containing insulation Box, PCM and heat sink could be effective in maintaining the temperature of TEG cold side down.

- The results exhibited that there is direct relationship between thermal gradient and generated power, i.e. a higher temperature difference produced more electrical energy.

- Based on power measurements, the energy harvester system generated continuously an average power output of $29 \mathrm{mWatt}$ per day.

The authors gratefully acknowledge the financial support from the Department of San Antonio CPS Energy.

\section{References}

1. Bobes-Jesus, V., Pascual-Muñoz, P., Castro-Fresno, D., Rodriguez-Hernandez, J. (2013). Asphalt solar collectors: a literature review. Applied Energy.102, 962-970.

2. Guo, L., Lu, Q. (2017). Potentials of piezoelectric and thermoelectric technologies for harvesting energy from pavements. Renewable and Sustainable Energy Reviews. 72, 761-773.

3. Chiarelli, A., Dawson, A., Garcia, A. (2015) Analysis of the performance of an air-powered energy-harvesting pavement. Transportation Research Record: Journal of the Transportation Research Board. 2523, 156-163.

4. Wu, G., Yu, X. (2012). System design to harvest thermal energy across pavement structure. IEEE Energytech. 1-4.

5. Datta, U., Dessouky, S., Papagiannakis, AT. (2017). Harvesting thermoelectric energy from asphalt pavements. Transportation Research Record: Journal of the Transportation Research Board. 2628:12-22.

6. Jiang, W., Xiao, J., Yuan, D., Lu, H., Xu, S., Huang, Y. (2018). Design and experiment of thermoelectric asphalt pavements with power-generation and temperature-reduction functions. Energy and Buildings. 169, 39-47.

7. LeBlanc, S. (2014). Thermoelectric generators: Linking material properties and systems engineering for waste heat recovery applications. Sustainable Materials and Technologies. 1,26-35.

8. Lau, P.G., Buist, R.J. (1997). Calculation of thermoelectric power generation performance using finite element analysis. Proceedings ICT'97. 16th International Conference on Thermoelectrics.

9. Liu, C., Chen, P., Li, K. (2014). A 1 KW thermoelectric generator for low-temperature geothermal resources. Proceedings, Thirty-Ninth Workshop on Geothermal Reservoir Engineering. 112. 